\title{
Continuous Steelmaking
}

Process metallurgists have long pictured the possibility of an integrated assembly of units which would accept the normal steelmaking raw materials and convert them continuously into steel, without requiring expensive cranes and ladles as needed in conventional batch processing. In this picture, liquid metal would flow by gravity from step to step.

Such a scheme has, of recent years, received considerable impetus through the efforts of Dr. Howard K. Worner, first as Research Director of Broken Hill Pty. and later in a similar position with Conzinc Riotinto, Ltd., both of Australia. Dr. Worner has received a number of patents in various countries, covering his contributions. The degree of interest in his proposals is indicated by the fact that Bethlehem Steel's Homer Research Laboratories have made extensive tests in a pilot refiner, converting hot metal (pig iron) to steel in a flowing stream. Also, the theoretical limitations on such a process have been developed by Prof. M. W. Thring, Queen Mary College, London.

The Journal of Metals is fortunate to be able to present, as a group, the following papers* covering these three subjects. All three relate to the essential heart of a complete processing sequence-namely, the continuous conversion of pig iron to steel, in which the liquid iron flows in a covered trough under successive jets of oxygen with continuous additions of slag-forming lime. In the preferred arrangement, slag flows counter-current to the steel with important consequences (as compared either to batch or concurrent flow): removal of sulfur and phosphorus is better, lime usage is lower and recovery of iron units is higher.

Dr. Worner's paper describes the various ways in which the continuous refiner can be combined with other continuous processes-blast furnace, cupola, electric melting of scrap or prereduced ore on the input end, and continuous casting from a holding furnace on the other. The latter is considered necessary when special alloying additions are to be made to satisfy the order book.

Dr. Rudzki details Bethlehem's experiments in quantitative terms, including some of the practical problems which had to be met. The conclusion of the study was that the process was technically feasible and possessed a number of advantages.

Prof. Thring, basing his theory on open hearth data, concludes that the launder (or trough) should have no more than one foot of width for each $10 \mathrm{tph}$ throughput, and that the length of the launder should be more than 30 times the depth. Under such conditions, forward mixing would be negligible, while there would be ample opportunity for the completion of the refining reactions. Although the experimental units, whose channel was about one foot wide, operated usually at less than the $10 \mathrm{tph}$ rate $(3-5 \mathrm{tph})$, both are said to be quite effective at $10-$ $15 \mathrm{tph}$.

Questions arise--and some were put forward when the Bethlehem paper was presented at the April 14 meeting of the NOH \& BOSC in Toronto-about refractory usage and difficulties in scaling up to commercial size. Actual experience is insufficient to establish conclusively a refractory pattern, although the protagonists see no insoluble problems. They point out that, in a continuous system, each brick is subject to a constant environment, in contrast to the changing conditions of a batch process. Scale-up is also believed to be fairly straight-forward. It was suggested by Dr. Worner that a single $2 \mathrm{ft} \times 2 \mathrm{ft}$ channel 50-60 ft long, with metal flowing at $2 \mathrm{fpm}$, should be capable of producing one million tons per year.

As a first step toward learning more about the scale-up problem, arrangements have been made, according to Dr. Worner, for a three-fold larger prototype to be built and tested in Sweden, under the auspices of the Jernkontoret. Future reports will be awaited with great interest.

John M. Gaines, Member Journal of Metals Advisory Committee

\footnotetext{
* The papers by Dr. Worner and Dr: Rudzki were presented at the 1969 National Open Hearth and Basic Oxygen Steel Conference in Toronto on April 14, 1969. Dr. Thring's paper was presented at the TMS-AIME Annual Meeting in WashConference in Toronto on
ington on February 17, 1969.
} 